\title{
THE INTERRENAL SYNDROME IN CHILDHOOD
}

\author{
BY \\ E. C. AllibONE, M.D., H. S. BAAR, M.D. and W. H. P. CANT, M.D. \\ (From the Children's Hóspital, Birmingham)
}

\section{FUNCTIONAL PATHOLOGY}

The adrenal cortex acts by the elaboration of a series of hormones which include among their functions the regulation of the electrolyte balance; carbohydrate, fat and protein metabolism; the development of the secondary sexual characteristics; and possibly the development of the gonads themselves. Although the action of many of these hormones is regulated by the pituitary, the latter gland has apparently little influence on that function of the adrenal which is essential for life, namely the regulation of the salt and water balance. An adrenalectomized animal quickly dies of the symptoms of Addison's disease, whereas hypophysectomy has not the same fatal outcome. This is in keeping with the generality that processes essential for life are, to a degree, autonomous (Swann, 1940).

The adrenal cortex is in a constant state of growth which takes place from without inwards. Throughout life new cells are being formed by multiplication of cells in the zona glomerulosa and from indifferent cells included in the capsule. The stage of growth takes place in the short zona glomerulosa. The cells then migrate inwards, forming the zona fasciculata, in the inner part of which and in the outer part of the ensuing zona reticularis the cells discharge their lipoid contents, possibly in part into a real glandular lumen continuous with the medulla (von Lucadou, 1938). The cells finally degenerate in the inner part of the reticulate zone (Zwemer et al., 1938).

After hypophysectomy the adrenal cortex atrophies in the reverse direction to which it grows. The atrophy progresses from within outwards. No definite histological abnormality occurs in the outermost zone (Crooke and Gilmour, 1938). It is to be presumed that this glomerular layer secretes the 'salt and water' hormone (Swann, 1940). Our own investigations on the appearance of doubly refractile lipoids in the adrenal cortex have shown that this takes place initially in a narrow zone in the region where the zona glomerulosa changes into the zona fasciculata.
In states of hyperfunction of the cortex, the resulting clinical and metabolic picture depends on the nature and amount of the hormones produced. Haymaker and Anderson (1938) suggested there were two syndromes, the adrenogenital, associated with virilism and representing the excessive production of androgens; and the adrenocortical, associated with the clinical picture of Cushing's syndrome and the excessive production of cortin. These views. have been supported and elaborated by Albright (1942), who concluded that the adrenogenital syndrome was due to an abnormal production of a ' $N$ ' hormone which, having an action similar to testosterone propionate, was produced in normal individuals after puberty concomitant with an increased excretion of 17-ketosteroids and was concerned with somatic and secondary sexual development. The adrenocortical syndrome, according to this author, was due to an excess of ' $S$ ' hormone which, acting by the inhibition of the synthesis of tissue, promoted the conversion of protein into sugar (glyconeogenesis) and inhibited the oxidation of glucose at the periphery.

The relationship between virilism and cortical hyperfunction is obvious. The aetiology of Cushing's syndrome was rendered debatable by the occasional occurrence of a basophil adenoma of the pituitary in this disease. However, Anderson and Haymaker (1937) were able to prolong the life of adrenalectomized rats by the injection of sera from two patients with Cushing's syndrome. Occasionally there is a disturbance of the electrolyte pattern the opposite to that occurring in Addison's disease (McQuarrie et al., 1937, Willson et al., 1940). Albright et al. (1941) produced amelioration of symptoms by giving testosterone, which is known to inhibit cortical function. The consensus of opinion is that Cushing's syndrome is due to adrenal cortical hyperfunction, the primary cause for which may arise either in the gland itself or be caused by an excess of adrenotropic hormone engendered by pituitary dysfunction.

The site of production of these groups of hormones is more speculative. Grollman (1936) considered 
that the androgenic hormones were produced by the transient cortex, which he compared with the $\mathrm{X}$ zone of the mouse. One has, however, to be cautious in considering the transient human cortex as homologous with any zone in other animals, because the whole process of late foetal and early post-foetal remodelling of the adrenal cortex in human beings is unique and differs from the development of the suprarenals in all other mammals.

Cahill et al. (1942) tried to correlate the hormonal changes with alteration in the cytology of the adrenal cortex. Tumours associated with hormonal change could not be identified with any particular zone, but the degree of vacuolation of the cortical cells was roughly proportional to the severity of the hormonal disturbance. The more the syndrome approached the Cushing type, the more marked was the amount of vacuoles which were present. Fuchsinophil staining of the cytoplasm was present in all tumours but was more pronounced in cases with hormonal syndromes. From the remarks of these authors that the fuchsinophil staining of the cytoplasm was in some cases diffuse, in others in granules, it is evident that their interpretation of the Ponceau-Fuchsin stain is different from that of Broster et al. (1938). The latter, who correlated the presence of fuchsinophil granules in the cells of the adrenal cortex with virilism, considered the presence of this fuchsinophil material to be related to the presence of androgen.

\section{CASE MATERIAL}

Unless otherwise stated, the cases recorded were collected from the records of the Children's Hospital, Birmingham, during the last ten years.

\section{Classification}

For the purposes of description it is proposed to use the following classification and terminology:

\section{ADRENOGENTTAL SYNDROME}

1. In the neonatal period.

(a) Pseudohermaphroditism in girls.

(b) Hyperplasia in boys.

2. In later childhood.

(a) Macrogenitosomia praecox in boys.

(b) Macrogenitosomia praecox with masculinization in girls.

\section{AdRENOCORTICAL Obesity (Cushing's syndrome)}

\section{The Adrenogenital Syndrome in the Neonatal Period}

Females born with adrenal hyperplasia show pseudohermaphroditism characterized by a clitoris enlarged to such a degree that it is usually considered to be a penis and the infants are registered as boys. The external orifice of the urethra may be at the tip of the penis or more towards its base as in hypospadias. There is usually no external vaginal orifice. A uterus of normal infantile dimensions with Fallopian tubes is present. The ovaries are in the usual site, the size being normal or reduced. As a rule a rudimentary vagina is found opening into the urethra. The scrotum may be bifid, but in many cases it is normal except for the absence of testicles. Thus the external genitalia may give rise to no suspicion that the individual is other than masculine in sex. In males there are no external abnormalities.

In neither sex do the infants thrive. Vomiting and diarrhoea are usually the predominating symptoms, with a tendency to sudden collapse which responds to the administration of saline or cortical extract. Such cases have been described by Di Ruggiero and Jolly (1938), Butler et al. (1939), Dijkhuizen and Behr (1940), Thelander and Cholffin (1941), and Skelton (1945). Both Butler et al. and Thelander and Cholffin considered the symptoms to be due to a deficiency of cortical hormone of the nature of Addison's disease. They demonstrated a low serum sodium and chloride with raised serum potassium. Butler's case was unusual in that a brownish pigmentation occurred all over the body at the thirteenth day. Thelander (1946) kept his patient alive until the age of seven with the aid of salt and desoxycorticosterone acetate therapy.

Female pseudohermaphroditism in the neonatal period (cases 1-5).

FAMILY History. In one case a sib, thought to be a hermaphrodite, had died in infancy from 'pyloric stenosis.'

History. Apart from one case which did not thrive from birth, the remainder took well and appeared to be satisfactory for the first seven to fourteen days, when they were found to be not gaining weight. Vomiting occurred in all cases. In one it was associated with diarrhoea and was considered to be due to a parenteral infection. In a further two it was not severe, but in two it was a dominant symptom and both cases were admitted with the provisional diagnosis of pyloric stenosis. All the infants gradually deteriorated. Ages at death were $17,25,35,44$, and 82 days. In two cases where radiographs were taken there was no premature ossification in carpus or tarsus.

MORBID ANATOMY. The external genitalia, except for a posteriorly incomplete prepuce, were of normal male týpe in one case. There was a definite hypospadias in four cases. The scrotum was recorded as being bifid in two cases. The vagina did not open externally except in one case, where it was situated posteriorly to the clitoris, was $2 \cdot 4 \mathrm{~cm}$. in length, and enclosed the vaginal portion of the cervix of the uterus. In four cases where the 
internal genitalia were mentioned, these consisted of a normal uterus, ovary, and Fallopian tubes.

The adrenals were hypertrophic, in some cases being larger than the kidneys. The surface was grossly corrugated. One was weighed and two were measured. In the one case the weight was $6.5 \mathrm{~g}$. for the right and 6.4 for the left adrenal. Normal weights are less than 7.0 g. for both adrenals (Dietrich and Siegmund, 1926). The size was larger than that of the kidney in two cases, and almost the size of the kidney in one case (Plate Ia). The normal size is about one-third that of the kidney.

The thymus was considered to be atrophic in two cases. In the others it was normal.

Body measurements were taken in two cases and were found to be normal, both with regard to length and proportion.

Histological Findings. The adrenals were examined in four cases. The transient and permanent cortex were present in varying amounts. The cytoplasm was mainly granular in both transient and permanent zones. In the case living for eighty-two days the cytoplasm was predominantly vacuolated. The Ponceau-Fuchsin stain was slightly positive in the oldest case, negative in the remainder.

The thymus was normal in one case. A second contained Hassal corpuscles which were occasionally enlarged.

The histology of the remaining organs contained nothing relevant. 6-10).

Hyperplasia in boys in the neonatal period (cases

FAMILY HISTORY. This was in all cases negative.

HisTORY. In three cases the initial symptom had been vomiting starting on the first, fourth, and tenth days of life respectively. There was an associated failure to gain weight. One case was weaned at three weeks because of failure to thrive, and developed diarrhoea four days later. The fifth case developed diarrhoea when twenty-five days old, and vomiting when thirty days old. On admission two cases, of which one had rapid respirations, were reported as being shocked. Three cases collapsed suddenly and died. A further case collapsed several times before death. Ages at death were $21,23,28,35$, and 45 days. In one case, and also in one of the female pseudohermaphrodites, repeated examination of the urine showed a persistance of chlorides in normal amounts in spite of intractable vomiting. Of three cases radiographed for premature ossification, only one showed a carpal centre just appearing at the age of twenty-one days.

MoRBID ANATOMY. The adrenals were hypertrophied, being usually as large as the kidneys. The surface was corrugated. The maximum weight of a single gland was $11.5 \mathrm{~g}$. The thymus was reported as atrophic in three cases, but no weights were given. The prostate was considered to be enlarged in three cases, in one case weighing $2 \cdot 3 \mathrm{~g}$. In three cases the testes were weighed, the combined weights being $2 \cdot 3 \mathrm{~g} ., 2 \cdot 27 \mathrm{~g}$., and $3 \cdot 8 \mathrm{~g}$. respectively. Body measurements taken in three cases were normal and proportional.

Histological Findings. The proportion of transient to permanent cortex was variable. The cytoplasm was on the whole granular. When vacuolation occurred it tended to be in the permanent cortex. The Ponceau+Fuchsin stain was positive in two cases and slightly so in a third.

The testes, examined in two cases, were of the immature type normal for the age. The thymus, examined in one case, contained Hassal's corpuscles, of which some were unusually large.

Adrenal hyperplasia was found on five occasions in association with other conditions, twice in haemolytic disease of the newborn, twice with exomphalos, and once with glycogen storage disease. In none of these cases was there any abnormality of the sexual organs.

Haemolytic disease of the newborn (cases 11-12). One case was a still-born male hydrops foetalis; the other was a male icterus gravis with haemorrhagic diathesis who died at the age of ten days of a severe widespread interstitial and haemorrhagic alveolar pneumonia. In both cases the adrenals were the size of the kidneys.

Histologically, in the case of the hydrops, the cells of the zona glomerulosa, zona fasciculata and transient cortex contained large vacuoles. Fuchsinophil granules were absent.

The cytoplasm of the adrenal in the case of icterus gravis was granular. The cells of the transient cortex nearly all contained fuchsinophil granules. Fuchsinophil granulation was scanty in the permanent cortex. The thymus in the latter case was peculiar in that the lymphoid tissue of the cortex was almost absent. The Hassal corpuscles were numerous, numbering approximately eight per high-power field.

Exomphalos (cases 13-14). In the first case a boy died aged one day after an attempt at operative repair. The second case died aged eighteen days having deteriorated gradually. In both cases the thymus was normal in size.

Histology of the adrenal in the first case showed the zona glomerulosa to be vacuolated and PonceauFuchsin negative. In the zona fasciculata and transient cortex the cytoplasm was granular and took the Ponceau-Fuchsin stain.

In the second case, which had a normal uterus, ovary, and Fallopian tubes, the cortical cytoplasm showed moderate vacuolation; granulation was slight and fuchsinophil staining moderately positive.

Glycogen storage disease and hyperplasia of the adrenals (case 15). A further case of adrenal hyperplasia was found incidentally in a still-born full-term male. The adrenals weighed $5.9 \mathrm{~g}$. and 
$7 \cdot 35 \mathrm{~g}$. The tarsus contained ossification centres in calcaneus and talus. The thymus was normal. The liver weighed $200 \mathrm{~g}$.

Histological Findings. The adrenal showed a well developed permanent cortex with a partly granular, partly vacuolated cytoplasm. The Ponceau-Fuchsin stain was slightly positive.

The liver cells were swollen, their outlines stained darkly, thus giving an impression of a cell membrane as in a plant cell. The cytoplasm was colourless with scattered groups of amphophil granules. The Best carmine stain showed most of the cells packed with carmine-positive granules although no special glycogen fixative had been used. These granules showed also a positive iodine reaction for glycogen (Plate Ib and c).

\section{The Adrenogenital Syndrome in Later Childhood}

Macrogenitosomia praecox in boys. Macrogenitosomia praecox in boys is relatively rare. Wilkins et al. (1940) collected from the literature eleven cases due to tumour. Their case was the first due to hyperplasia which had come to autopsy. A further case due to hyperplasia was reported by Thelander (1946). Although the tumours are usually carcinomata and run a short course, it is possible that hyperplasia may occur without a fatal outcome. Cahill et al. (1942) reported two boys who had had signs of macrogenitosomia praecox for seven or eight years. Both had reached the stage of fusion of epiphyses with resulting dwarfism.

Typically, boys with the adrenogenital syndrome show accelerated muscular and secondary sexual development with advanced ossification and excessive secretion of 17 -ketosteroids. The prostate is hypertrophied, but the testes enlarge only slightly if at all and remain immature. If these cases do not die, the epiphyses fuse prematurely with consequent stunting.

The following case is reported by kind permission of Mr. E. R. Flint and Professor M. J. Stewart of Leeds.

Case 16. B. C. was admitted at the age of 2 years.

FAMILY HISTORY. The parents were cousins.

Personal History. The birth weight was $7 \frac{3}{4} \mathrm{lb}$. The boy sat up at seven months, walked at sixteen months, and began to say odd words at eighteen months. His general intelligence was thought to be not quite up to normal. He had always been a large child. Two months before admission he was thought to be developing too quickly, hair had appeared on the pubes, and the genitalia had enlarged. For some weeks spots had been noticed on his chest. He used to 'touch himself'. The bowels were generally constipated. Recently there had been some diarrhoea.

EXAMINATION. Examination showed a muscular child, height 36 in., weight $43 \mathrm{lb}$. He looked to be about five years old. His voice was deep for a child. In the ward he was strong and active. There was hair on the pubes, and the genitalia were enlarged and the testes descended. The penis erected on stimulation but there was no seminal secretion. A radiograph of the skull showed no abnormality. Fasting blood sugar was $90 \mathrm{mg}$. per $100 \mathrm{ml}$. Blood pressure was $105 / 75 \mathrm{~mm}$. Hg. (Plate Id).

A laparotomy was performed. Both adrenals were found to be enlarged. The left was removed and weighed $12 \cdot 9 \mathrm{~g}$. Death occurred twelve hours after operation.

MORBID ANATOMY. The right adrenal weighed $12.3 \mathrm{~g}$. Weights of testes were: left, $1.85 \mathrm{~g}$.; right, $1 \cdot 21 \mathrm{~g}$. The prostate was larger than normal, weighing $3.37 \mathrm{~g}$. The thymus was fleshy and succulent, weighing $32 \mathrm{~g}$. The tonsils were slightly enlarged. The mesenteric glands and Peyers' patches were enlarged and hypertrophied. In the duodenum there was an acute healing ulcer $3 \mathrm{~mm}$. in diameter on the anterior surface $8 \mathrm{~mm}$. below the pylorus. The ventricles of the heart were both hypertrophic. The remaining organs were normal.

Histological Findings. Large areas of the adrenals had the structure of transient cortex. Such vacuolation as was present was confined to the zona glomerulosa. In the latter, only an occasional cell with a positive Ponceau-Fuchsin stain was seen, but those of the zona fasciculata were positive and took the stain with the same intensity as the transient cortex. The stain was much brighter in the operation specimen. The colouring of the autopsy specimen was more of a brick red shade.

The thymus showed a sharply demarcated and well developed cortex and medulla. An occasional haemorrhage was seen in the cortical zone. There were 1-12 Hassal's corpuscles per lobule, ranging in size from 13 to 181 microns (Plate IIe).

The prostate had the structure of an adult gland with numerous large alveoli separated by narrow septa. The mucous membrane was folded with papilliform processes and high columnar epithelium.

The testes measured $14 \mathrm{~mm}$. by $5.5 \mathrm{~mm}$., and $19 \mathrm{~mm}$. by $9.4 \mathrm{~mm}$. They contained several adrenal rests of the foetal type, measuring up to $2.5 \mathrm{~mm}$. in diameter, which took the PonceauFuchsin stain with the same brick colour as the adrenal taken from the autopsy. The structure of the testis was otherwise normal for a child. The epididymis and vesiculae seminales were normal.

A differential cell count was made of the pituitary after the method of Rassmussen and Herrick (1922). In 17,000 cells there were: eosinophils 50 per cent., basophils $2 \cdot 5$ per cent., chromophobes $47 \cdot 7$ per cent.

The vesicles of the thyroid were large and filled with colloid. The one parathyroid examined was normal, consisting entirely of water-clear chief 
cells. The duodenum showed a healed ulcer., The remaining organs were normal.

Macrogenitosomia praecox in girls. Macrogenitosomia praecox in girls presents a varying degree of masculinization. The mildest cases show little more than hypertrophy of the clitoris. The most severe present a picture of pseudohermaphroditism so advanced that the individuals are reared as boys, the hypertrophied clitoris being mistaken for a hypospadic penis and the labia majora for empty scrotal sacs.

Case 17. D. J. had been brought up as a boy. He was admitted to the surgical side at the age of 6 years 10 months for the repair of a complete hypospadias. He had the features of a child of 12 or 14 years. The 'penis' was well formed and there was a complete hypospadias, the urethral opening being one inch below the root of the 'penis.' There was a small empty 'scrotum.' Pubic hair was well marked. Some axillary hair was also present.

A suprapubic cystotomy was performed. ' His' condition initially remained good, but he collapsed eighteen days after the operation and died four days later. At autopsy the pelvis contained a vagina leading to an infantile uterus, Fallopian tubes, and ovaries. The suprarenals were enlarged. The thymus appeared normal. No other abnormality was detected.

Histology. The adrenals had the structure of the transient cortex except for a narrow zona glomerulosa. Only in the latter zone were vacuoles present. Sections stained with Ponceau-Fuchsin showed the cortex to be packed with fuchsinophil granules (Plate IIf).

Case 18. E. B., aged 11 years, had previously attended the hospital when five months old with an imperforate vagina. Recently she had developed some hoarseness of the voice and her general interests had been more those of a boy than a girl.

General examination showed the child to be big for her age, her features slightly masculine, and the skin coarse. The trunk had a male contour (Plate IIg). The mammary glands were undeveloped but the nipples were normal. The external genitalia showed a female distribution of pubic hair which was excessively present for a girl of this age. The vulva appeared normal but the clitoris was much enlarged. The child had no vaginal orifice. The opening of the urethra was in the perineum and situated at the base of the clitoris. No testes were palpable in the inguinal canals. On rectal examination a small hard mass, thought to be the uterus, was palpable anterior to the rectum. The 24-hour urinary 17 -ketosteroid excretion was $28.7 \mathrm{mg}$. A radiograph of the carpus showed eight well developed centres. The pisiform bone was large. The secondary centre at the base of the first metacarpal had already fused with the shaft (normal 14 to 21 years).

An exploratory laparotomy revealed two normal ovaries, Fallopian tubes, and a uterus which appeared infantile but was normal as far as the cervix. There was no evidence of a vagina. The right suprarenal appeared normal in size and shape, but the left suprarenal was considerably enlarged. This enlargement appeared to be a general hyperplasia of the suprarenal rather than an adenoma.

A left suprarenalectomy was subsequently performed. Convalescence was stormy.

Table 1 gives the serum electrolyte levels taken before, twelve days after, and twenty-six days after the adrenalectomy.

Thirty days after the operation the daily urinary 17-ketosteroid excretion was $27 \mathrm{mg}$. A month later this had fallen to $17 \cdot 2 \mathrm{mg}$., but eight months after the adrenalectomy it was $29.7 \mathrm{mg}$. There had been neither psychological nor clinical change.

Histology OF THE ADRENAL. This differed from the other cases in having a well developed permanent cortex. The gland was both vacuolated and granular, but the vacuolation was mainly in the permanent cortex. The granular cells gave a positive Ponceau-Fuchsin reaction.

TABLE 1

BLOOD SODIUM AND POTASSIUM LEVELS IN A CASE OF VIRILISM SUBJECTED TO UNILATERAL ADRENALECTOMY (CASE 18)

\begin{tabular}{c|c|c}
\hline $\begin{array}{c}\text { Time relationship } \\
\text { to the operation }\end{array}$ & $\begin{array}{c}\text { Blood sodium } \\
\text { in m.e. per } 100 \mathrm{ml} .\end{array}$ & $\begin{array}{c}\text { Blood potassium } \\
\text { in m.e. per } 100 \mathrm{ml}\end{array}$ \\
\hline 9 days before & 133 & $5 \cdot 2$ \\
12 days after & 130 & $8 \cdot 0$ \\
26 days after & 107 & $8 \cdot 5$ \\
(Normal range) & $139-152$ & $4 \cdot 1-4 \cdot 6$ \\
\hline
\end{tabular}

\section{Adrenocortical Obesity (Cushing's Syndrome)}

Cushing's syndrome as it appears in childhood is almost always due to a tumour of the adrenal. In a review of the literature Marks et al. (1940) collected twenty-four cases, of which twenty-one were in girls. The clinical picture may differ slightly from that in adults: The obesity need not be of the 'buffalo' type but may be generalized. Hirsutism is the next most constant finding. Osteoporosis is not seen and the glucose tolerance is normal. A tendency for the cases to be of a mixed type is seen in the enlarged clitoris in eleven cases, precocious menstruation in two, and the occasional occurrence of acne. The youngest case was that described by Lightwood (1932), aged eleven weeks.

In the two cases to be described, extreme obesity was the symptom dominating the clinical picture. The only genital abnormality was a slight pubic hirsutism in one case. 
Case 19. E. W., admitted at the age of 9 months, had no relevant family history. The neck was noticed to be full at five months. - A month before admission she was considered to be overweight. She was happy and contented but made no attempt to crawl. Apart from the obesity, the physical examination was negative. The height was 29 in., the weight $31 \mathrm{lb}$. (Plate IIh).

Oral and intravenous tolerance curves were normal. Radiographic examination showed that secondary centres were appearing in the lower tibia, in the fibula and radius, and at the upper and lower ends of the humerus. Two approximately normalsized ossification centres were present in the carpus.

Fatal pneumonia developed after exploratory laparotomy. At autopsy the left adrenal was found to be small. The right was replaced by a large soft mass (Plate IIIj).

Histology. The tumour consisted of cells, oval, polyhedric, approximately spherical, occasionally of a broad fusiform or whetstone shape. The majority of the cells had a diameter of approximately $9 \cdot 25$ microns. The cytoplasm was wide, forming between two-thirds to three-fifths of the cell. Only in the smallest cells was the cytoplasmic rim narrow, with cytoplasm and nucleus about equal in diameter. The cytoplasm was either uniformly purplish or finely granular, but in some cells was definitely vacuolated. In some small areas the cells were highly vacuolated. The nuclei were hyperchromatic and spherical. Only occasional nucleoli were seen with the Haemalum and Eosin stain, but with Masson's trichrome and the Ponceau-Fuchsin stain definite fuchsinophil nucleoli were seen in almost all nuclei. These nucleoli varied in size. In some cells almost the whole nucleus was filled with a spherical large fuchsinophil globular mass resembling an inclusion body. In areas of necrosis numerous such fuchsinophil globules were seen. These pathologically enlarged nucleoli were not stained by the Lundrum stain which is supposed to be specific for inclusion bodies. In many cells, especially in the oval-shaped, the nucleus was eccentric. Most of the cells had one nucleus, but there were a fair number of multinucleated cells, some of the larger cells having as many as a dozen nuclei. In some of the latter there were, instead of nuclei, spherical, rod- or horse-shoe shaped bodies taking up the nuclear stain and suggesting atypical mitosis. In one area there was an arrangement of cells somewhat suggestive of those in an adrenal cortex. Numerous patchy areas of necrosis were present, and in some areas whole tumour tissue was transformed into a uniform mass staining pale blue. The vascularization of the tumour was poor and the arrangement of the cells had in some areas, where there was little dissociation of the cells, a definite epithelial pattern. The Foot stain showed scanty argentophil fibres almost entirely limited to the blood vessels and separating alveoli of the cells described above.
Case 20. M. A., aged 20 months, had no relevant family history. When six months old she was noticed to be red in the face. At eight months she became fatter. Pubic hair was noticed at nine months. She was otherwise well and goodtempered. She began to talk at thirteen months.

On admission she was found to be placid with expressionless face. She stood with support. Her height was 28 in., her weight $30 \mathrm{lb}$. (Plates IIIk, 1). Apart from the generalized obesity nothing abnormal was found clinically. Oral glucose, intravenous glucose, and insulin depression curves were normal. Radiographs showed two carpal centres, a centre at the lower end of the tibia, and at the lower and upper ends of the humerus.

Laparotomy revealed a left adrenal mass which was removed. The patient died the next day with signs of pneumonia.

At autopsy the right adrenal was not definitely located. Histological examination of the perirenal tissue disclosed a gland $7.8 \mathrm{~mm}$. long by $0.5 \mathrm{~mm}$. broad and two adjacent nodules 1.2 by $0.3 \mathrm{~mm}$. and 1.0 by $0.4 \mathrm{~mm}$. The structure was that of the adult cortex. The cytoplasm was well vacuolated. The hypoplasia affected mainly the zona fasciculata and the zona reticularis. The Ponceau-Fuchsin stain was negative (Plate IIIm). The tumour had on histological examination a structure almost identical with that of the previous case.

The lobules of the thymus were small, with increase of interstitial connective tissue. Hassal's corpuscles numbered 1 to 10 per lobule and had a diameter of 26 to 70 microns.

The basophil cells of the pituitary showed the hyaline changes described by Crooke (1935), over 90 per cent. of these cells being affected to a greater or less degree. A differential count $(19,500$ cells) gave the following proportions: eosinophils $35 \cdot 5$ per cent., basophils $4 \cdot 2$ per cent., chromophobes $60 \cdot 3$ per cent. (Plate IVn and $p$ ).

\section{DISCUSSION}

\section{The Adrenogenital Syndrome}

Broster et al. (1938), who consider the presence of fuchsinophil granules in the adrenal cortex to be related to the presence of androgen, found in their study of the foetal adrenal cortex that fuchsinophil granules were present in the male foetus between the ninth and twentieth weeks of gestation and in the female from the eleventh to the fifteenth weeks. The disappearance of fuchsinophil granulation coincided with the appearance of basophil cells in the pituitary. These authors explained the occurrence of female pseudohermaphroditism on the prolongation of this masculinizing phase over the whole period of intrauterine life.

Adrenal hyperplasia in the newborn appears to be approximately equally distributed between the two sexes. The cases of Di Ruggiero and Jolly (1938), Thelander and Cholffin (1941), Butler et al. 
(1939), and Skelton (1945) were all boys. Two of the four cases reported by Dijkhuizen and Behr (1940) were boys. In Thelander and Cholffin's case a sib had died with similar symptoms and was thought to be a female pseudohermaphrodite. One of the male infants in Dijkhuizen and Behr's series had a male sib who died with symptoms suggestive of adrenal hypofunction. Di Ruggiero and Jolly's boy had had three sibs, all boys, who died respectively at the age of thirty-two, forty, and sixty-one days with chronic vomiting and failure to gain weight attributed to various causes. One of our pseudohermaphrodites had had a sib reported as being a hermaphrodite and who had died of " pyloric stenosis.' In our series there were five of each sex. This apparently equal distribution between the sexes, together with the comparatively frequent reports of familial occurrence, suggests that there is an inherited factor determining the hyperplasia of the suprarenals and that this factor is not sex linked.

The elaboration of the abnormal masculinizing hormone is apparently associated with a failure to produce the more essential 'salt and water' hormone. This has been likened to acute Addison's disease both on account of the blood electrolyte picture (Butler et al., 1939) and because of the results of treatment with salt and desoxycorticosterone (Thelander and Cholffin, 1941). Pigmentation of the skin actually occurred in Butler's case. In early infancy the hyperplasia of the suprarenal glands is often associated with a fairly characteristic clinical syndrome. This consists of failure to thrive, persistent severe vomiting which may be projectile and suggestive of pyloric stenosis (two of our cases), faeculent and suggesting intestinal obstruction (Dijkhuizen and Behr, 1940). Attacks of acute circulatory failure resembling shock are frequent and were stressed by Harris (1946) and other authors. Four of our male cases showed this liability to sudden collapse. The rapid respiration in one of the male cases recalled the syndrome of acute adrenal insufficiency in the newborn due to haemorrhage into the gland, which Goldzieher and Gordon (1932) referred to as 'pseudopneumonia.'

The diagnosis is not difficult provided the possibility is considered. It may be made on the blood levels of sodium, potassium, and chloride, or on the dramatic response to salt and hormone therapy. In a neonate with hypospadias and absence of testes in the scrotum, attacks of acute circulatory failure should raise suspicions. In male babies the lead is less obvious. Acute collapse is not uncommon in a poorly infant. In two of the authors' cases a special note was made of the persistence of urinary chloride in spite of continued vomiting. This may be considered to be an excessive urinary chloride excretion comparable to that in Addison's disease. With the growing appreciation of the importance of the rôle of salts in tissue fluids, the urine is likely to be tested as a routine for chlorides more frequently in the future than it has been in the past. It is suggested that, in an obscure case of intractable vomiting, if the chlorides do not virtually disappear from the urine, adrenal cortical hypofunction should be considered to be a possibility. In the neonatal period this may occur not only in cortical hyperplasia but as a temporary phenomenon, when it is presumably due to birth trauma (Jaudon, 1946).

There is ample experimental evidence that the adrenal cortical hormones are concerned with the regulation of carbohydrate metabolism. Adrenalectomy leads to a mobilization of the glycogen in the tissues, and the liver becomes practically glycogen free. Administration of cortical extract, on the other hand, increases. the liver glycogen. In vitro, glycogenolysis is inhibited by cortical extract, hypoglycaemia being produced notwithstanding large glycogen depots. It would appear suggestive that in case 15 , with glycogen storage disease, the cortical hyperplasia was associated with an increased production of those cortical hormones which, like corticosterone, have an oxygen atom at $\mathrm{C}_{11}$.

As far as is known the association of adrenal hyperplasia with glycogen storage disease has not been hitherto described, though the possibility was suggested by Long (1942). In fact Ellis and Payne (1936) in a review of the literature of von Gierke's disease, found three cases with adrenal hypoplasia but, in the majority of cases, the adrenal was normal. It is, of course, purely hypothetical to draw conclusions from a single case, but in future more attention should be paid to the glycogen content of the liver in suprarenal cortical hyperplasia.

It is a striking fact that, although interrenal pseudohermaphrodites surviving for several years show invariably evidence of precocious growth and ossification, these children are normal in size at birth. In none of the reported cases was the baby stated to be particularly big at birth. We have paid special attention to this point. All our cases in the neonatal period were normal in size and in none of the five cases in which $x$-ray examination was carried out was there any evidence of precocious ossification.

There are a number of possibilities which might explain the postnatal onset of the somatic as distinct from the sexual disturbance. Firstly, the suprarenal hormones are not responsible for growth and ossification directly, but act through changes in such glands with internal secretion as are known to have an influence on growth and ossification, such as the pituitary and the gonads. The latter, however, have shown no changes in our cases. The pituitary has to be further investigated, but the fact that hyperfunction of eosinophil cells in the anterior pituitary lobe is associated with giantism and delayed union of epiphyses, while in macrogenitosomia praecax the rapid growth leads to a precocious ossification of the epiphyseal lines and results finally in a dwarfed stature, makes such an explanation improbable.

Secondly, there are different hormones in the suprarenal cortex influencing the development of the 


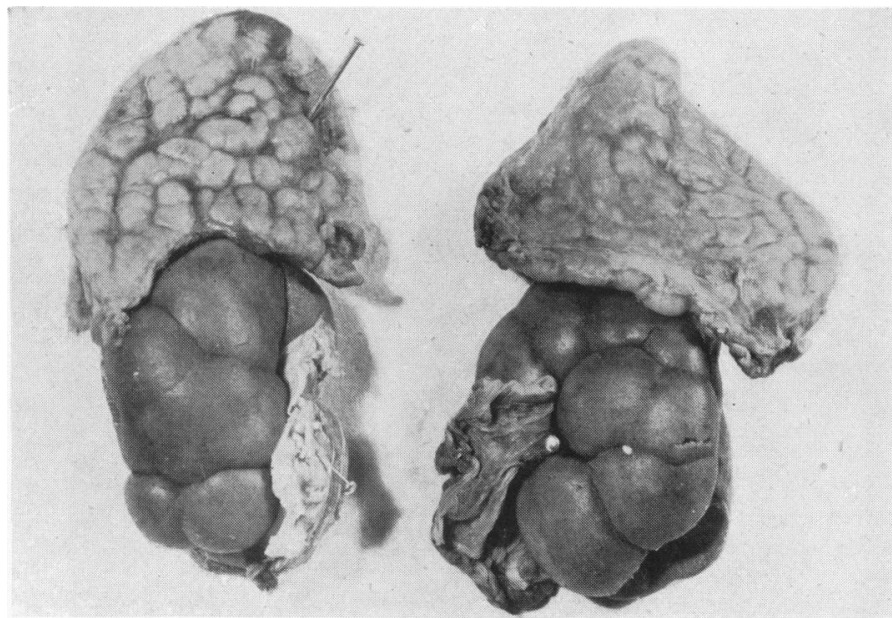

(a) top left-Enlarged adrenal glands due to hyperplasia.

(d) right-Macrogenitosomia praecox in a boy due to adrenal hyperplasia (case 16).

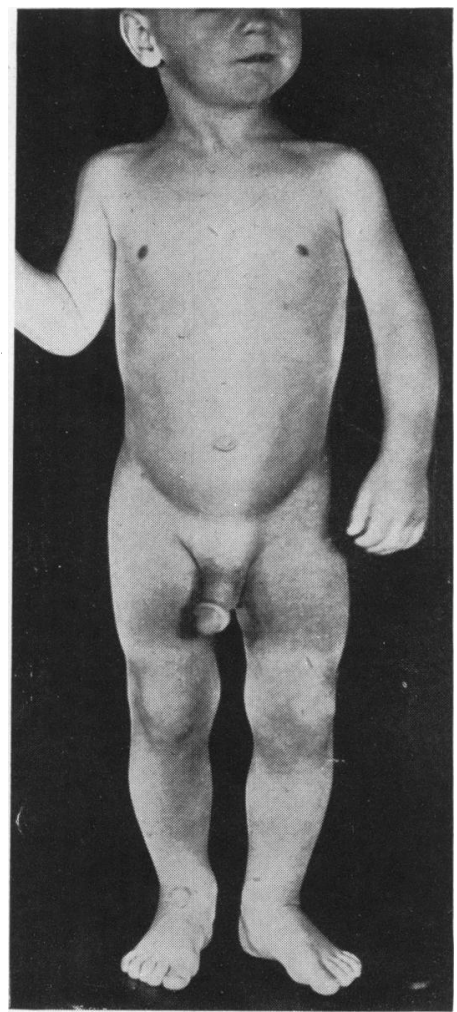

(b) lower left-Liver of case 15 , with glycogen storage disease, showing the characteristic plant like appearance of the swollen liver cells. Haematoxylin and Eosin.

(c) lower rightLiver of case 15 , with glycogen storage disease, showing liver cells filled with glycogen. Best's Carmine stain. 


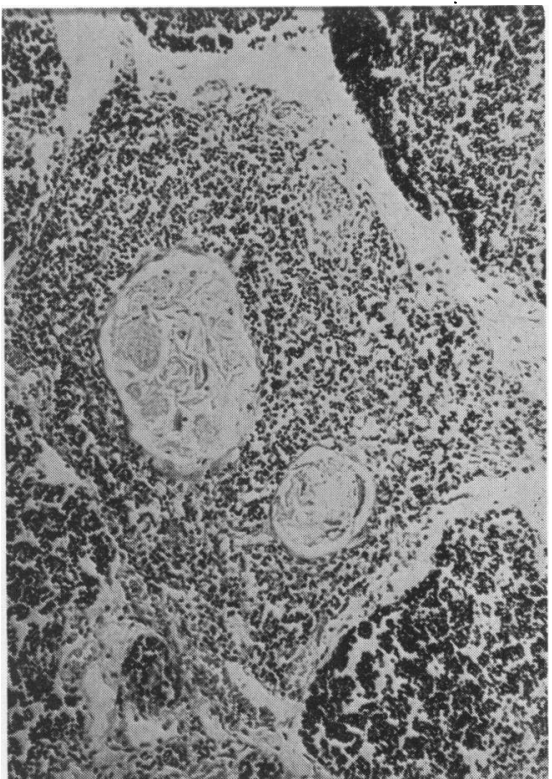

(e)-Thymus from case 16, macrogenitosomia praecox in a boy, showing enlarged Hassal's corpuscles. Haematoxylin and Eosin.

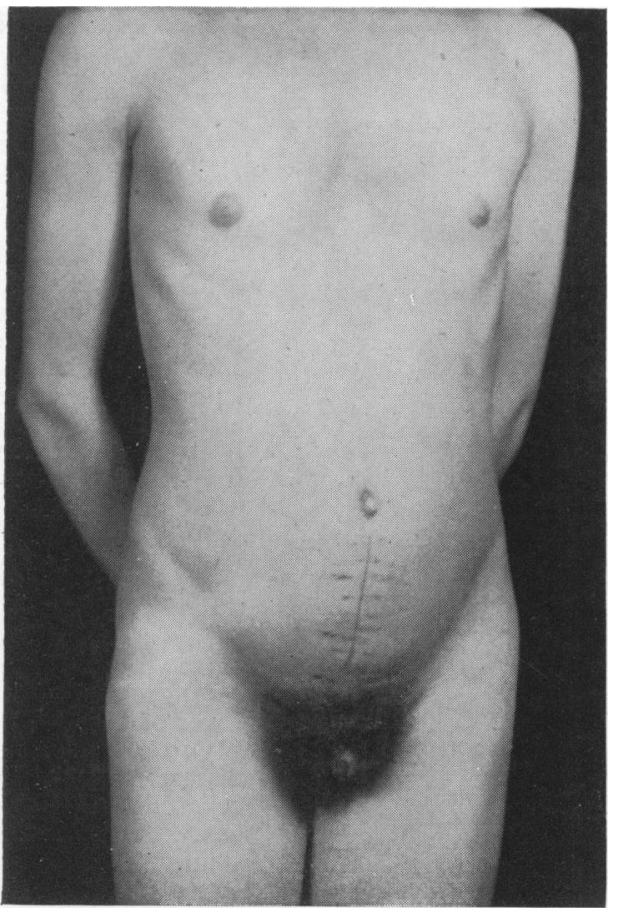

(g)-Masculine configuration in a female pseudohermaphrodite (case 18).

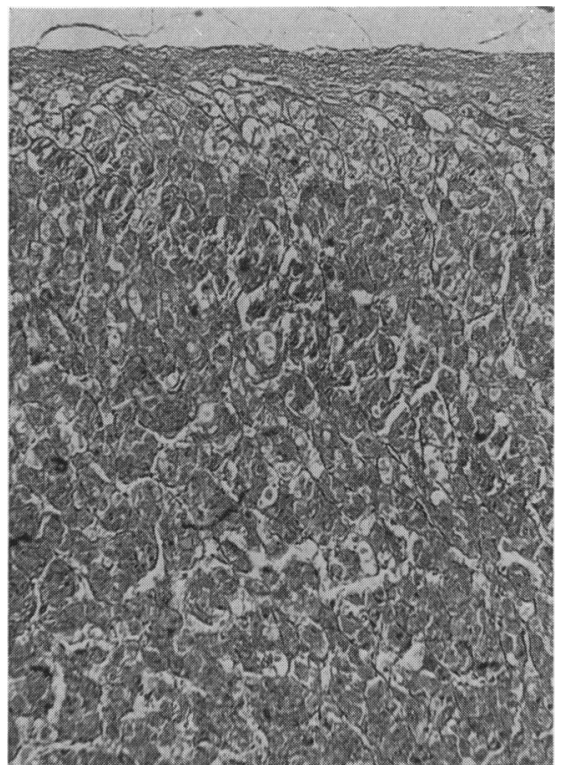

(f)-Low-power microphotograph of the adrenal cortex in pseudohermaphroditism (case 17), showing predominance of a transient cortex composed of granular fuchsinophil cells. Ponceau-Fuchsin stain.

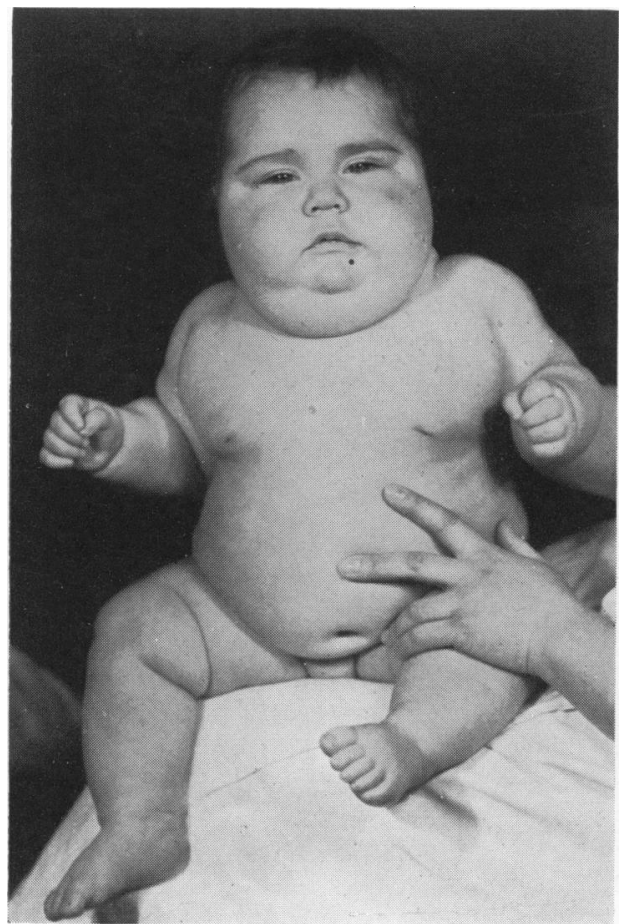

(h)-Generalized obesity in Cushing's syndrome (case 19).

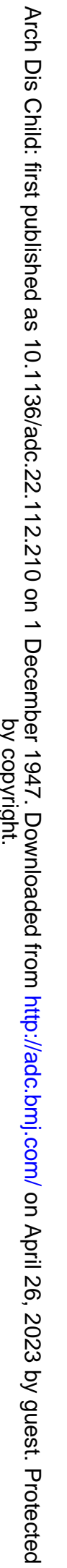




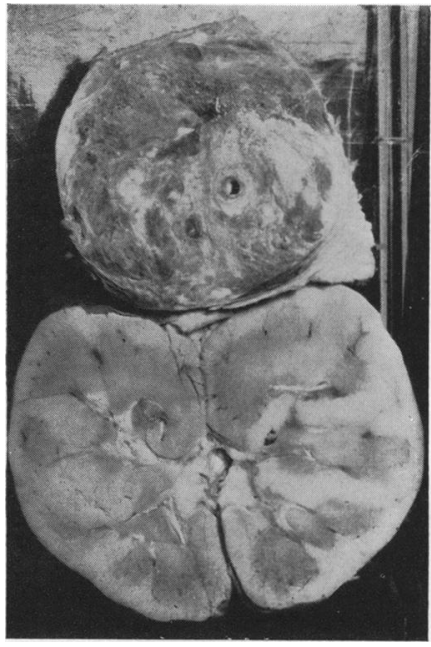

(j) top left-Carcinoma of adrenal causing Cushing's syndrome (case 19).

(k) top right-Plethoric facies and generalized obesity in Cushing's syndrome (case 20).

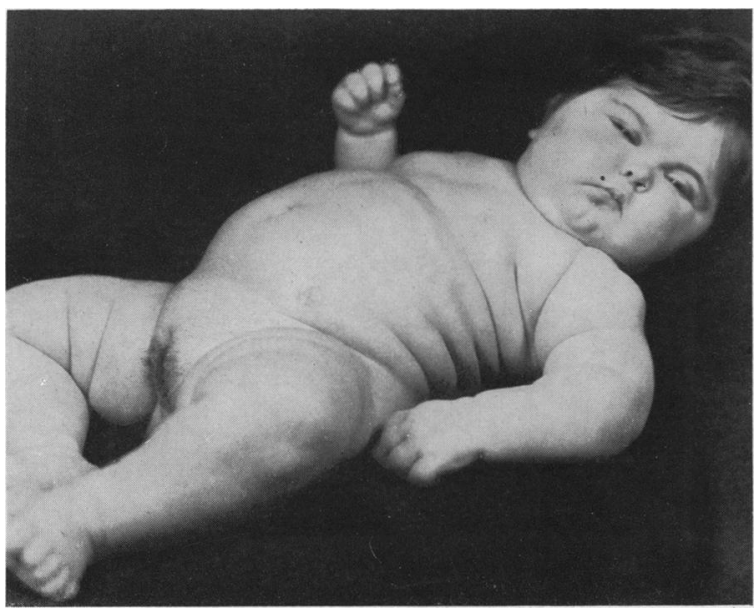

(1)-Hirsutism in Cushing's syndrome (case 20).

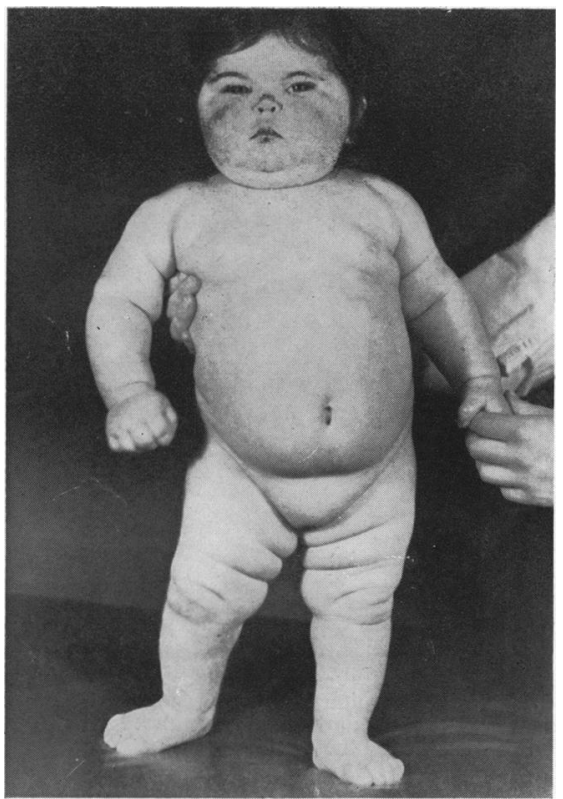

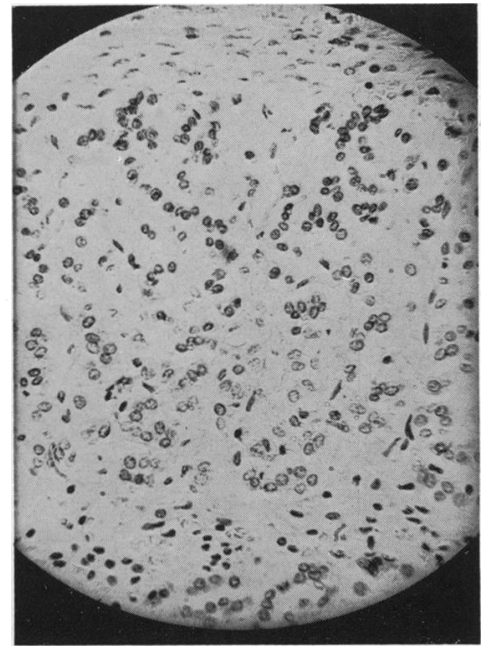

(m)-The contralateral gland to an adrenal carcinoma causing Cushing's syndrome (case 20), consisting solely of an atrophic adult cortex made up of vacuolated cells. Haematoxylin and Eosin.

\section{PLate III}




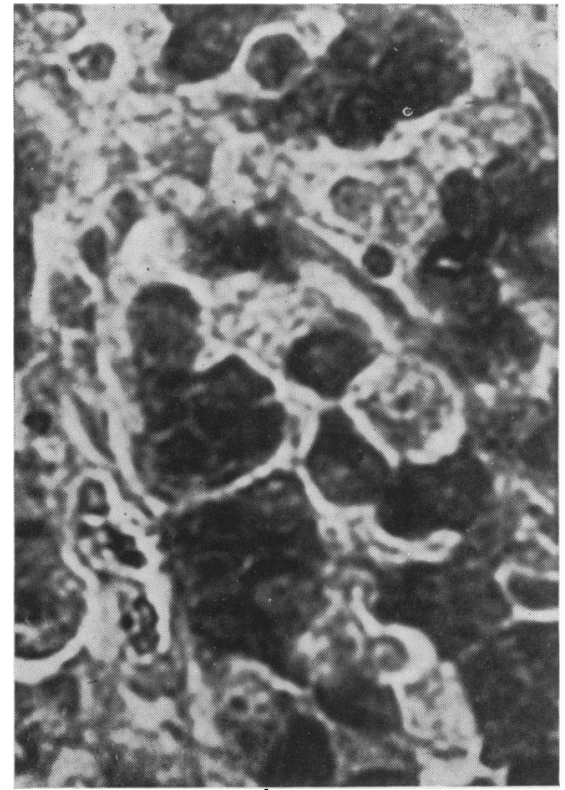

(n)-Normal pituitary, showing groups of basophil cells packed with dark blue granules. High power. Mann's methylene blue Eosin.

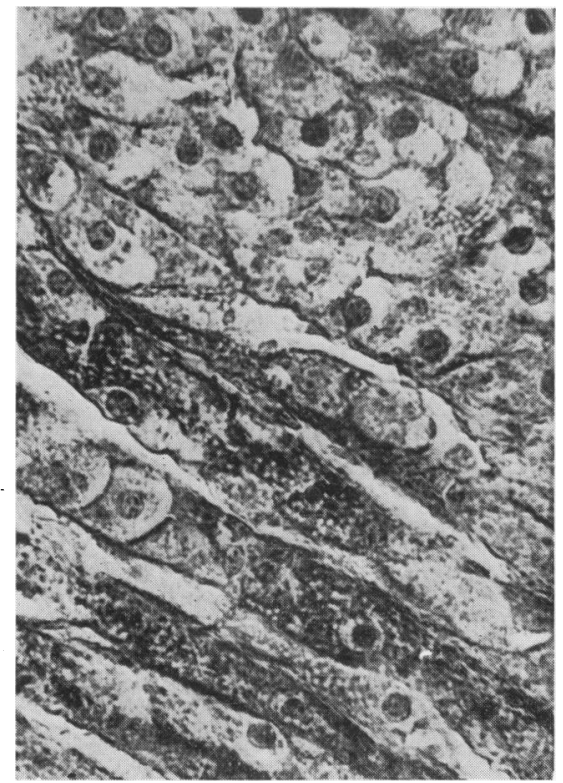

(q)-High-power microphotograph of the adrenal cortex to show granular and hyaline cytoplasm existing contiguously. Ponceau-Fuchsin stain.

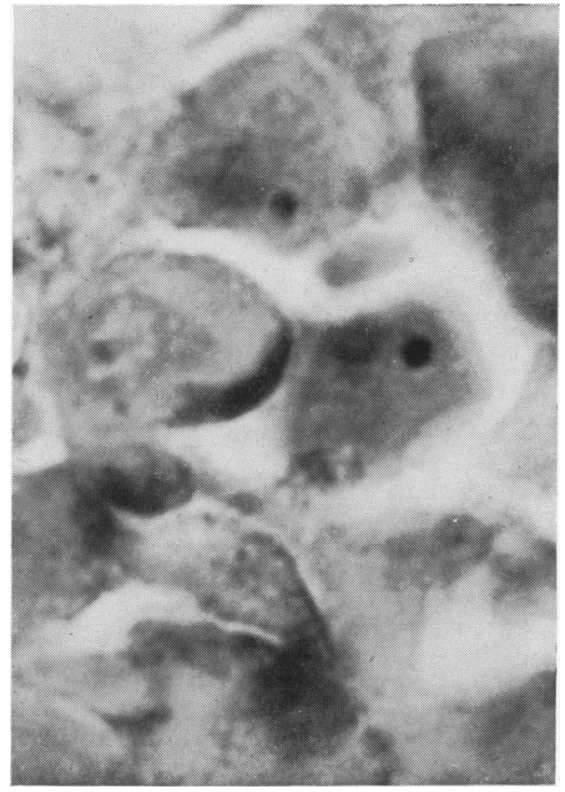

(p) - Pituitary basophil cells in Cushing's syndrome (case 20). The basophilic granulation has been largely replaced by a pale grey hyaline cytoplasm. Oil immersion. Mann's methylene blue Eosin.

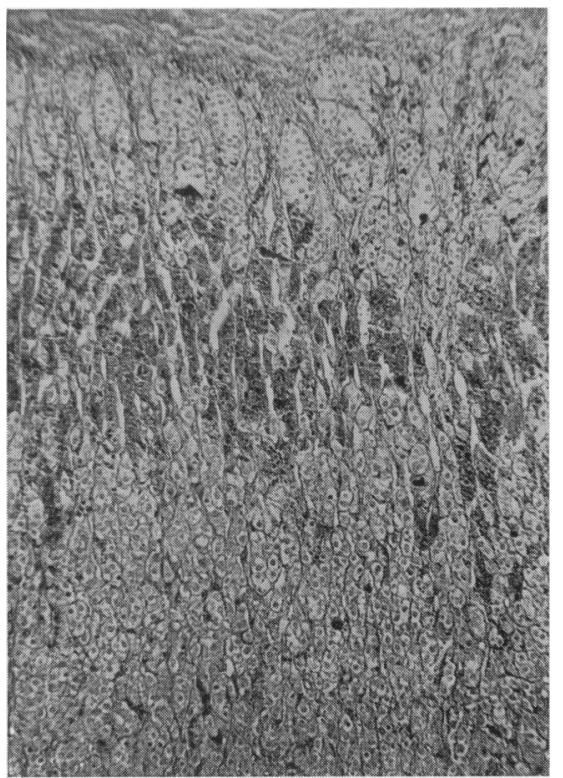

(r)-Permanent cortex in a pseudohermaphrodite (case 18), showing a band of granular fuchsinophilic cystoplasm (dark) in the peripheral part of the zona fasciculata. Ponceau-Fuchsin stain. 
secondary sexual characters on the one hand and bone growth on the other, the latter being formed in later childhood. Although there is no experimental evidence for the existence of two such hormones, Venning and Kazmin (1946) found that the proportions of the individual hormones produced by the adrenal cortex varied with the age of the child.

Thirdly, the action of the suprarenal hormones depends on the developmental stage of the effector organs.

Fourthly, some maternal hormones may counteract the growth-promoting effect of the suprarenal hormones and their action may still manifest itself for some time after birth.

Fifthly, the histological work of von Lucadou (1938) strongly suggested that the suprarenal cortex and medulla, although phylogenetically and ontogenetically different organs, form a functional entity in higher mammals. Some of the suprarenal hormones appear to be secreted through glandular lumina into the medulla, and the medullary secretion may modify the action of the cortical hormones. The adrenal medulla, being only a small part of the entire organ in the newborn, and increasing in size not only absolutely but relatively, may thus be responsible for the different effects of cortical hormones in foetal and early neonatal life on the one hand, and later childhood on the other.

In the authors' opinion there is at present insufficient evidence to give preference to any of these hypotheses.

The adrenogenital syndrome appearing in later childhood may be due to either hypertrophy or to tumour, usually carcinoma, of the adrenal.. These cases, however, occur predominantly in girls. Goldstein et al. (1946) collected from the literature fifty-four cases of carcinoma of the adrenal cortex which showed the adrenogenital syndrome. Of these, twelve were boys. The disproportion between the sexes becomes even more pronounced when cases of adrenal cortical hyperplasia are considered, a condition which occurs almost exclusively in girls. Up to the present there have been only two cases reported in boys where the cause of the macrogenitosomia praecox was proved to be due to a hyperplasia (Wilkins et al., 1940; Thelander, 1946). It is likely that Thelander's case would not have survived beyond infancy if it had not been treated with salt and desoxycorticosterone. The sex difference was so striking as to make Thelander and Cholffin (1941) raise the question whether these cases of female pseudohermaphrodites, with marked hypertrophy of the ' androgenic' zone but without marked symptoms of cortical insufficiency, belonged to the same etiological group.

Another possible explanation may lie in the effect of synergistic and antagonistic hormones on cortical function causing a higher survival rate among the females with cortical hyperplasia than among the males. Testosterone has been shown to inhibit adrenal cortical function (Albright, 1942).
Oestrone not only causes adrenal hypertrophy, but pregnancy and oestrus favour the survival of adrenalectomized animals. Further, pituitary implants prolong the life of adrenalectomized female animals but not of the adrenalectomized male or of the adrenalectomized female castrate (Goldzieher, 1945a). If the male infant were to produce testosterone and the female infant oestrone, even in small amounts, the effect of these hormones might be such as to tip the balance in favour of the survival-of the female.

\section{The Adrenocortical Syndrome}

Our two cases of suprarenal cortical carcinoma support the conception of the existence of tumours with different hormonal action. Both showed an extreme obesity, but neither masculinization nor precocious growth. Some of the cortical tumours, however, in the literature appear to have produced both 17-ketosteroids, causing masculinization, and metabolic hormones causing obesity. This may be due to a primary mixed hormone production, or the elevated 17-ketosteroid formation may represent a compensatory increase in an attempt to counteract the pathologically elevated ' $S$ ' hormone production, as has been suggested for Cushing's syndrome in the adult by Albright (1942).

\section{Sudden Death in Adrenocortical and Adrenogenital Dysfunction}

In cases of Cushing's syndrome due to an adrenal cortical tumour, Cahill et al. (1942) stressed the liability of the function of the contralateral gland to be suppressed, resulting in the danger of sudden death from acute adrenal insufficiency if the tumour were removed. This contrasted with the bilateral adrenal hyperplasia seen in cases of virilism in adult women.

That a tumour can not only cause a suppression of function, but that it can be associated with a contralateral atrophy of the adrenal is well seen in case 20 , where the opposite gland measured $8.0 \mathrm{~mm}$. by $0.5 \mathrm{~mm}$. and was not found on naked-eye examination, although the perirenal fat was thoroughly dissected and examined. While it is agreed that in virilism in adult women portions of the adrenals can be removed safely and with amelioration of symptoms (Broster, 1946), the possibility exists that, as both glands are being stimulated to form androgens, they may fail to produce adequate amounts of the more vital hormones. This is clearly so in the infantile cases of hyperplasia. It might account for the death in case 17, the six-year-old pseudohermaphrodite for whose rapid decease no other adequate cause was found. In considering case 16 , the male macrogenitosomia praecox who died twelve hours after a left adrenalectomy, the recent history of diarrhoea. may have been an indication of an incipient metabolic breakdown. This assumption finds further 
support from the condition at autopsy of the thymus, which was fleshy and succulent, weighing $32 \mathrm{~g}$.; and the mesenteric glands and Peyer's patches, enlarged and hypertrophied, were suggestive of a diminished function of the adrenal (Goldzieher, 1945b). Thelander's case (1946) of macrogenitosomia praecox at the age of seven years, was killed by measles within twenty-four hours in spite of a previously adequate salt and desoxycorticosterone therapy. A possible cause for the stormy convalescence of case 18 after left adrenalectomy is shown in the serum sodium and potassium values, the latter figures, in particular, suggesting a cortical hypofunction.

The eventuality of acute adrenal failure should, therefore, be kept in mind when dealing with any case of possible cortical hyperplasia in children, although the danger is likely to be more pronounced in cases of suprarenal neoplasm with obesity.

\section{Histology of the Adrenal Cortex in Hyperplasia}

In the newborn period the appearance of the glands was very variable. In places there was a well marked permanent cortex. At other sites in the same gland the tissues had the structure of the transient cortex except for a narrow band of zona glomerulosa. The cytoplasm was equally variable, in parts granular, in others vacuolated (Plate IVq). The transient cortex tended to be the more granular, the permanent cortex the more vacuolated, but on the whole we had the impression that in the cases with adrenal cortical hyperplasia the cell types with the cytoplasm showing fine granules in haemalum and eosin stains was prevalent, while cells with a vacuolated cytoplasm, especially those with large vacuoles, formed only a small part of the cortical tissue. The Ponceau-Fuchsin stain was often negative. This may be due to the fact that most of our material was obtained at necropsy. The influence of post-mortem changes on the result of the Ponceau-Fuchsin stain was obvious in case 16, where one adrenal was obtained at operation, the other after death. Broster et al. (1938) pointed out that the presence of fuchsinophil granulation was only an indication of androgenic material present at the time of fixation and gave no index of the previous activity of the gland. Further, Vogt (1943) found that the amount of cortical hormone continually being excreted was enormous when compared with the quantity which could be extracted from the gland tissue. Thus, either the methods of extraction were inadequate or the adrenal cortex did not store its principles in active form. In the latter event a discharge of hormone without new formation, even for a very short time after death, would thus explain the frequent occurrence of negative Ponceau-Fuchsin staining in autopsy material. When positive the stain was more noticeable in the transient cortex.

Where there were nodules of adenomatous hyperplasia the structure might be that of either transient or permanent cortex. In the latter case there was not the usual zonal demarcation. In the hydrops foetalis the vacuolation of the cortical cells, particularly the transient cortex, was gross.

In the adrenogenital syndrome in older children the cortex was mainly transient in cases 16 and 17, and Vines' Ponceau-Fuchsin reaction was positive. In the older case of virilism (case 18), there was a well developed permanent cortex. The cells were both vacuolated and granular but the vacuolation was mainly in the permanent cortex. Granular cytoplasm in both types of cortex gave a positive Ponceau-Fuchsin stain (Plate IVr).

These findings, and those in the case of Cushing's syndrome, are in agreement with the observation of Broster et al. (1938) that the fuchsinophil material is not limited to a zone of tissue in the juxtamedullary region which Grollman (1936) considered to be the androgenic zone. The fuchsinophil material, when present, occurred only in those cells showing acidophil granules with haemalum and eosin. Vacuolated cells, considered by Cahill et al. (1942) to be typical of the Cushing type of syndrome, did not show fuchsinophil granules.

Summarizing all our histological findings, including a series of normal newborn adrenals examined for the presence of Sudanophil material, for anisotropic lipoids, and by the Ponceau-Fuchsin stain, it appears that the transient type of cortex is more concerned with the formation of androgenic hormones than is the permanent cortex. There is some relationship between the presence of fuchsinophil granules and androgenic function, but the latter is not limited to a particular type of cortical tissue nor to cells with a definite morphology.

\section{The Pituitary in Relation to the Adrenogenital and} Adrenocortical Syndromes

Since Cushing (1932) described the association of a basophil adenoma of the pituitary with the syndrome to which subsequently his name was attached, the latter condition has also been found in conjunction with both tumours and hyperplasia of the adrenal glands. The clinical picture of Cushing's syndrome is so clear cut that there is presumably some common factor in the etiology. As patients with cancer of the adrenals and Cushing's syndrome are probably suffering primarily from an hyperadrenocorticism of some kind, then, on the assumption of a uniform pathological basis, all patients with Cushing's syndrome are suffering from hyperadrenocorticism (Albright, 1942). In these cases the only constant finding in the pituitary is a hyalinization of the cytoplasm of the basophil cells, described by Crooke (1935). Kepler (1945) considered these changes to be secondary to the adrenal hyperplasia, being in the nature of the effects of depression of function of the basophil cells which were considered to secrete the adrenotropic agent. Marks et al. (1940), in a review of the literature of adrenocortical obesity in children, quoted one case 
as having hyaline changes in the basophil cells of the pituitary, though in their own case there was a slight increase in the number of acidophil as compared with the basophil cells. These hyaline changes were well shown in case 20 (Plate IVp).

It is of particular interest in this connexion that partial hypophysectomy causes a hyperplasia of the adrenal cortex in rats, associated with an increased amount of body fat and at the same time changes in the cells of the pituitary remnants which are apparently identical with those described by Crooke and observed in case 20 (Reiss et al., 1937). Total hypophysectomy, on the other hand, causes an atrophy of the suprarenal cortex involving mainly the inner zone of the cortex (Crooke and Gilmour, 1938; Swann, 1940). The bulk of evidence appears to support the idea that the pituitary changes are secondary to the suprarenal hyperplasia. The frequent dogmatic statement that the basophil cells of the pituitary anterior lobe are the site of the formation of adrenocorticotropic hormones, appears to be not fully justified, as adrenal hyperplasia was also described in acromegaly by Fischer (1926).

There is no clear relationship between the adrenogenital syndrome and changes in the cells of the anterior pituitary. Wilkins et al. (1940), in their case of macrogenitosomia praecox in a male associated with cortical hyperplasia, reported a relative preponderance of basophil cells. Reilly et al. (1939), reviewing forty cases of ' pseudo-sexual precocity' in preadolescent girls, stated that the pituitary was alleged to be normal in two cases, there was an eosinophil adenoma once, a colloid cyst and atrophy once, cystic hypoplasia once. These authors did not, however, make a clear distinction between the adrenogenital and the adrenocortical syndromes, possibly because the clinical picture is so often mixed.

Where the material was available, differential cell counts were made after the method of Rasmussen and Herrick (1922). The stain used was Mann's methylene blue eosin.

The only modification was in the number of fields counted. Rasmussen examined every - fifth field in every fifth row, in this way counting between $10-30,000$ cells per gland. In order to count this number of cells in the smaller glands it may be necessary to count every fourth field in every fourth row or even every third field in every third row.

The results of the differential counts are given in table 2. It is felt the results are too few to draw any conclusions, as these figures are within the range of normal for adults (Rasmussen, 1929, 1933).

\section{Thymus}

The thymus undergoes rapid involution in any condition where there has been a call on the adrenal hormones. Conversely the thymus shows hyperplasia in the case of chronic disease or hypoplasia of the adrenals. The atrophy of the thymus frequently found in cases of interrenal pseudohermaphroditism was by several authors considered to be a result of adrenal cortical hyperplasia, being the antithesis of thymic persistence in Addison's disease. We feel that such a conclusion is not supported by facts. Our infantile cases showed marked atrophy of the thymus in five out of ten cases, but that is a common finding in infants after prolonged disease.

Hornowski (1926) found in newborn infants that a prevalence of epithelial elements of the thymus was associated with an inhibition of suprarenal development, while a prevalence of lymphatic elements was associated with a normal development of the suprarenals. It may, therefore, be of some significance that in our cases 6 and 16 there were enlarged Hassal bodies.

\section{Diagnosis of the Adrenogenital and Adrenocortical Syndromes}

The diagnosis of the adrenocortical syndrome has to be made from other forms of obesity, and has been discussed by Marks et al. (1940). The tumour may be difficult to palpate because of the obesity. Perirenal insufflation of air has been successfullyused to delineate the mass.

The adrenogenital syndrome has to be distinguished in the male from pineal, midbrain and hypothalamic, testicular, and thymic tumours; in the female from midbrain, hypothalamic and thymic tumours, and arrhenoblastoma and granulosa cell tumours of the ovary. The differential diagnosis of

TABLE 2

DIFFERENTIAL CELL COUNTS OF THE PITUITARY

\begin{tabular}{|c|c|c|c|c|c|}
\hline $\begin{array}{l}\text { Case } \\
\text { No. }\end{array}$ & Condition & $\begin{array}{l}\text { Eosinophils } \\
\text { per cent. }\end{array}$ & $\begin{array}{l}\text { Basophils } \\
\text { per cent. }\end{array}$ & $\begin{array}{l}\text { Chromophobes } \\
\text { per cent. }\end{array}$ & $\begin{array}{c}\text { Total cells } \\
\text { counted }\end{array}$ \\
\hline $\begin{array}{l}- \\
4 \\
6 \\
15 \\
16 \\
20\end{array}$ & 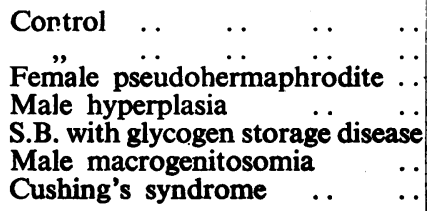 & $\begin{array}{l}14 \cdot 4 \\
14 \cdot 0 \\
25 \cdot 7 \\
13 \cdot 3 \\
15 \cdot 3 \\
50 \cdot 0 \\
35 \cdot 5\end{array}$ & $\begin{array}{r}10 \cdot 0 \\
2 \cdot 7 \\
18 \cdot 8 \\
9 \cdot 1 \\
4 \cdot 8 \\
2 \cdot 3 \\
4 \cdot 2\end{array}$ & $\begin{array}{l}75 \cdot 6 \\
83 \cdot 3 \\
55 \cdot 5 \\
77 \cdot 6 \\
79 \cdot 9 \\
47 \cdot 7 \\
60 \cdot 3\end{array}$ & $\begin{array}{r}14,837 \\
22,636 \\
11,720 \\
21,304 \\
9,792 \\
17,249 \\
19,532\end{array}$ \\
\hline
\end{tabular}


these conditions has been considered by Goldstein et al. (1946), Kepler and Keating (1941), Goldzieher (1945c), and Soffer (1946).

Of help in the confirmation of the diagnosis in the adrenogenital syndrome is the increase of the urinary 17-ketosteroids, premature ossification as shown by radiograph, and the examination of biopsy material. For reasons already discussed, the Ponceau-Fuchsin stain seems to be more reliable with specimens taken at operation than at autopsy.

Although the adrenogenital syndrome shows frequently such a characteristic clinical entity that the diagnosis presents no difficulty, cases are occasionally encountered in which adrenal hyperplasia can be neither diagnosed nor definitely excluded. This is well illustrated by one of our cases, a girl aged three years, not previously quoted, where the clinical signs were an enlargement of the clitoris since the age of two years, precocious ossification without increased rate of growth, hirsutism, or increased urinary output of 17ketosteroids, and without any evidence of intracranial disease.

\section{SUMMARY}

From a review of the case material of the Birmingham Children's Hospital during the last ten years, ten cases of adrenal hyperplasia in the newborn with symptoms of adrenal cortical hypofunction are described, and the symptomatology and the diagnosis discussed. The estimation of the urinary chloride as a diagnostic aid is emphasized. The differences in the clinical picture between the adrenogenital syndromes in the newborn and in older children are pointed out.

Five further cases of adrenal hyperplasia in the newborn are described, two in haemolytic disease of the newborn, two with exomphalos, and one stillborn with glycogen storage disease.

The adrenogenital syndrome in older children is represented by three cases, all due to hyperplasia. One boy presented the typical picture of macrogenitosomia praecox. The two girls were both pseudohermaphrodites.

Two girls with adrenocortical obesity or Cushing's syndrome due to adrenal cortical carcinoma are described.

The liability of the above cases to sudden death is stressed.

An attempt is made to correlate the two syndromes with histological changes in the adrenal cortex. Although the proportion of transient to permanent cortex was very variable in adrenal hyperplasia in the newborn, the transient cortex predominated in the adrenogenital syndrome in older children but was completely absent in the atrophic contralateral adrenal to the carcinoma in Cushing's syndrome.
Fuchsinophil material, when present, was predominantly in the transient cortex and was probably concerned with the production of androgens, whereas the cytoplasm of the permanent cortex was mainly vacuolated and presumably concerned with adrenocortical hormone production.

The relationship of the pituitary and thymus to the interrenal syndrome is discussed.

Our thanks are due to the Honorary Staff of the Children's Hospital, Birmingham, for permission to publish their cases, to Mr. A. R. Detheridge for the microscopical sections, and to Mr. J. Gregory Williamson for the photographs.

\section{REFERENCES}

Albright, F. (1942). The Harvey Lectures, 38, 123.

Albright, F., Parson, W: and Bloomberg, E. (1941): J. clin. Endocrinol., 1, 375.

Anderson, E. M. and Haymaker, W. (1937). Science, 86, 545.

Broster, L. R. (1946). Proc. roy. Soc. Med., 40, 35.

—_, Allen, C., Vines, H. W. C., Patterson, J., Greenwood, A. W., Marrian, G. F. and Butler, G. C. (1938). The Adrenal Cortex and Intersexuality. Chapman and Hall, Ltd. London.

Butler, A. M., Ross, R. H. and Talbot, N. B. (1939). J. Pediat., 15, 831 .

Cahill, G. F., Melicow, M. M. and Darby, H. H. (1942). Surg. Gynec. Obstet., 74, 281.

Crooke, A. C. (1935). J. Path. Bact., 41, 339.

Crooke, A. Gilmour, J. R. (1938). Ibid., 47, 525.

Cushing, H. (1932). Johns Hopk. Hosp. Bull., 50, 137.

Di Ruggiero and Jolly, A. (1938). Ann. d'Anat. path., 15, 332.

Dietrich, A. and Siegmund, H. (1926). In Henke and Lubarsch: Handb. path. Anat. Histol., Berlin, 8, 964.

Dijkhuizen, R. K. and Behr, E. (1940). Acta paediat., 27, 279.

Ellis, R. W. B. and Payne, W. W. (1936). Quart. J. Med., 29, 31.

Fischer, B. (1926). Quoted by Dietrich, A. and Siegmund, H., in Henke and Lubarsch: Handb. path. Anat. Histol., Berlin, 8, 985.

Goldstein, A. E., Rubin, S. W. and Askin, J. A. (1946). Amer. J. Dis. Child., 72, 563.

Goldzieher, M. A. (1945a). The Adrenal Glands in Health and Disease. F. A. Davis, Company. Philadelphia. p. 123. (1945b). Ibid., p. 278. (1945c). Ibid., p. 470. and Gordon, M. B. (1932). Endocrinology, 16, 165.

Grollman, A. (1936). The Adrenals. Baillière, Tindall and Cox. London.

Harris, C. (1946). Arch. Dis. Childh., 21, 178.

Haymaker, W. and Anderson, E. (1938). International Clinics, 4, 244.

Hornowski (1926). Quoted by Dietrich, A. and Siegmund, H., in Henke and Lubarsch: Handb. path. Anat. Histol., Berlin, 8, 1016.

Jaudon, J. C. (1946). J. Pediat., 29, 696. 
Kepler, E. J. (1945). J. clin. Endocrinol., 5, 70. and Keating, F. R. Jr. (1941). Arch. intern. Med., 68, .1010 .

Lightwood, R. (1932). Arch. Dis. Childh., 7, 35.

Long, C. N. H. (1942). Endocrinology, 30, 870.

Lucadou, W. von (1938). Beitr. path. Anat., 101, 197.

McQuarrie, I., Johnson, R. M. and Ziegler, M. R. (1937). Endocrinology, 21, 762.

Marks, T. M., Thomas, J. M. and Warkany, J. (1940). Amer. J. Dis. Child., 60, 923.

Rassmussen, A. T. (1929). Amer. J. Path., 5, 263. (1933). Ibid., 9, 459.

and Herrick, R. (1922). Proc. Soc. exp. Biol. N.Y., 19, 416.

Reilly, W. A., Lisser, H. and Hinman, F. (1939). Endocrinology, 24, 91.
Reiss, M., Epstein, H. and Gothe, I. (1937). Z. ges. exp. Med., 101, 69.

Skelton, M. O. (1945). Arch. Dis. Childh., 20, 135.

Soffer, L. J. (1946). Diseases of the Adrenals. Kimpton, London, p. 245.

Swann, H. G. (1940). Physiological Reviews, 20, 493.

Thelander, H. E. (1946). J. Pediat., 29, 213.

- and Cholffin, M. (1941). Ibid., 18, 779.

Venning, E. H. and Kazmin, V. (1946). Endocrinology, $39,131$.

Vogt, M. (1943). J. Physiol., -102, 341.

Wilkins, L., Fleischmann, W. and Howard, J. E. (1940). Endocrinology, 26, 385.

Willson, D. M., Power, M. H. and Kepler, E. J. (1940). J. clin. Invest., 19, 701 .

Zwemer, R. L., Wotton, R. M. and Norkus, M. G. (1938). Anat. Rec., 72, 249. 